\title{
Enablers of Physician Prescription of a Long-Term Asthma Controller in Patients with Persistent Asthma
}

\author{
Francine M. Ducharme, ${ }^{1,2,3}$ Alexandrine J. Lamontagne, ${ }^{2}$ Lucie Blais, ${ }^{4}$ \\ Roland Grad, ${ }^{5}$ Kim L. Lavoie, ${ }^{6,7}$ Simon L. Bacon, ${ }^{6,8}$ Martha L. McKinney, ${ }^{2}$ \\ Eve Desplats, ${ }^{9}$ and Pierre Ernst ${ }^{10,11}$ \\ ${ }^{1}$ Department of Pediatrics, University of Montreal, Montreal, QC, Canada H3T 1C5 \\ ${ }^{2}$ Clinical Research and Knowledge Transfer Unit on Childhood Asthma, Research Centre, CHU Sainte-Justine, \\ Montreal, QC, Canada H3T 1C5 \\ ${ }^{3}$ Department of Social and Preventive Medicine, University of Montreal, Montreal, QC, Canada H3C 3J7 \\ ${ }^{4}$ Department of Pharmacology, University of Montreal, Montreal, QC, Canada H3T 1J4 \\ ${ }^{5}$ Department of Family Medicine, McGill University, Montreal, QC, Canada H3T 1E2 \\ ${ }^{6}$ Montreal Behavioural Medicine Centre, Hôpital du Sacré-Cour de Montreal, Montreal, QC, Canada H4J 1C5 \\ ${ }^{7}$ Department of Psychology, Université du Québec à Montreal, Montreal, QC, Canada H3C 3P8 \\ ${ }^{8}$ Department of Exercise Science, Concordia University, Montreal, QC, Canada H4B 1R6 \\ ${ }^{9}$ Research Centre, CHU Sainte-Justine, Montreal, QC, Canada H3T 1C5 \\ ${ }^{10}$ Divisions of Clinical Epidemiology and of Pulmonary Medicine, Department of Medicine, Jewish General Hospital, \\ Montreal, QC, Canada H3T 1E2 \\ ${ }^{11}$ Department of Medicine, McGill University, Montreal, QC, Canada H4A 3J1
}

Correspondence should be addressed to Francine M. Ducharme; francine.m.ducharme@umontreal.ca

Received 14 December 2015; Accepted 10 May 2016

Academic Editor: Alice M. Turner

Copyright (C) 2016 Francine M. Ducharme et al. This is an open access article distributed under the Creative Commons Attribution License, which permits unrestricted use, distribution, and reproduction in any medium, provided the original work is properly cited.

Objective. We aimed to identify key enablers of physician prescription of a long-term controller in patients with persistent asthma. Methods. We conducted a mailed survey of randomly selected Quebec physicians. We sent a 102-item questionnaire, seeking reported management regarding one of 4 clinical vignettes of a poorly controlled adult or child and endorsement of enablers to prescribe long-term controllers. Results. With a 56\% participation rate, 421 physicians participated. Most (86\%) would prescribe a long-term controller (predominantly inhaled corticosteroids, ICS) to the patient in their clinical vignette. Determinants of intention were the recognition of persistent symptoms (OR 2.67), goal of achieving long-term control (OR 5.31), and high comfort level in initiating long-term ICS (OR 2.33). Decision tools, pharmacy reports, reminders, and specific training were strongly endorsed by $\geq 60 \%$ physicians to support optimal management. Physicians strongly endorsed asthma education, lung function testing, specialist opinion, accessible asthma clinic, and paramedical healthcare professionals to guide patients, as enablers to improve patient adherence to and physicians' comfort with long-term ICS. Interpretation. Tools and training to improve physician knowledge, skills, and perception towards long-term ICS and resources that increase patient adherence and physician comfort to facilitate long-term ICS prescription should be considered as targets for implementation.

\section{Introduction}

Guided self-management is the cornerstone of the management of adults and children with asthma [1-4]. Five evidencebased recommendations for guided self-management were endorsed in national and international asthma guidelines: prescription of long-term controller medication for those with persistent asthma; provision of self-management plans; regular medical review; environmental control of known triggers; and asthma education $[1-3,5]$. Suboptimal management results in frequent exacerbations, preventable hospitalizations, unsafe use and abuse of medications, absenteeism, 
and even death [6-8]. Yet, fewer than $30 \%$ of patients with persistent asthma use daily controller medications or have a written self-management plan $[9,10]$. Although some of the responsibilities lie with the patient, physicians are also at fault as fewer than half of physicians report basing their treatment recommendations on the national asthma guidelines $[9,11,12]$. Barely two-thirds of physicians self-report recommending daily inhaled corticosteroids (ICS) in patients with persistent asthma [10], and most physicians prescribe only short courses of ICS [13-15] or provide insufficient prescription renewals to allow long-term use of ICS [16, 17].

Several studies have addressed barriers to physician adherence to asthma guidelines including use of asthma controllers [18-22], but few, if any, specifically addressed long-term therapy. Yet, the identification of relevant barriers is insufficient by itself to design an effective intervention. Indeed, many knowledge translation initiatives were unsuccessful or only modestly effective because the tested intervention did not address the relevant barriers or lacked a foundation in behavioural theory supporting the intervention $[23,24]$. Thus, one must ensure that solutions are effective and implementable by the target audience. Seeking physicians' enablers and proposed solutions has emerged as an effective approach to identify such interventions [25]. In a recent qualitative study, we identified a large number of enablers proposed by physicians to optimise asthma care [26]. Marked variation across physician specialties in prescription patterns and reported barriers suggest the need to target interventions to specific settings and/or specialties $[18,19,22$, 27]. High endorsement of promising enablers by physicians and identification of operational behavioural targets are thus keys to designing a successful intervention to improve their practice $[24,28,29]$.

Our main objective was to quantify physicians' endorsement of promising enablers to facilitate the prescription of long-term ICS. We also wished to ascertain physicianreported behaviour regarding the prescription of long-term asthma controller in a poorly controlled patient with persistent asthma and the determinants of this behaviour.

\section{Methods}

2.1. Study Design. The current paper reports the survey of randomly selected Quebec physicians treating patients with asthma. The protocol received approval from the Institutional Review Board of the Sainte-Justine University Health Centre. All participants received an information letter and consent was assumed if they returned the completed questionnaire.

2.2. Participants. Physicians were eligible if they were registered in July 2013 with the College des Médecins du Québec as family medicine physicians, pediatricians, or emergency physicians and held an active practice licence. Physicians were excluded if they had obtained their diploma more than 30 years earlier, were not practicing, were not seeing patients with asthma, were in training, or had participated in the questionnaire pretest; the former criteria was meant to exclude physicians most likely to be retired by the time a specific knowledge translation intervention would be ready for testing. Physicians were randomly selected using a stratified sampling procedure based on specialty.

\subsection{Materials}

2.3.1. Item Generation. In the first phase of the study [26] where we conducted qualitative semistructured interviews of 42 physicians, we identified 867 enablers of optimal guided self-management and specifically of the prescription of longterm ICS.

2.3.2. Item Reduction. We retained enablers most frequently endorsed by interviewed physicians; among those, a 2-step Delphi approach was conducted among 7 coauthors with expertise in pediatric and adult respirology, family medicine, pediatrics, pharmacoepidemiology, and behaviour change to identify enablers most likely to be implementable.

2.3.3. Presentation and Scaling. The self-report questionnaire had five main sections. The first section served to describe the characteristics and practice setting of physicians. In the second section, participants were asked to select one of 4 clinical vignettes that most closely reflected their practice, namely, a school-aged child or an adult with poorly controlled asthma who presented either for an acute exacerbation or in the clinic setting when stable (Table E1 in Supplementary Material available online at http://dx.doi.org/10.1155/2016/4169010). Based on the selected vignette, participants were asked to report their treatment recommendations and follow-up strategy (i.e., behaviour), assessment of asthma control and phenotype (i.e., knowledge and skills), and treatment objectives (i.e., goals). The third section pertains to physicians' comfort level in performing key tasks associated with optimal asthma management (i.e., confidence about capabilities), perceived risk-benefit associated with prescription of longterm ICS for certain groups of patients (i.e., knowledge of risk-benefit), and endorsement of resources to assist in patient-specific decision-making and/or patient's adherence to ICS. The fourth and fifth sections, pertaining to written action plans and pharmacists' professional activities, are the object of other reports. Responses were recorded on a 6-point Likert scale ranging from 0 to 5.

2.3.4. Pretesting for Clarity. Pretested in six physicians, the questionnaire took between 20 and 30 minutes to be complete. It was endorsed by and included the logos of the Institut National d'Excellence en Santé et Services Sociaux (INESSS), Association des Pédiatres du Québec, Association des Spécialistes en Médecine d'Urgence du Québec, and Fédération des Médecins Omnipraticiens du Québec.

2.3.5. Survey Procedures. Using the Tailored Design Methods [30], a prenotification postcard was sent, followed 10 days later by the information letter, questionnaire, and a \$25 cheque, a thank you/reminder postcard on day 21 , and, for nonresponders, a second questionnaire on day 37, followed by up to three phone calls. Where feasible, another physician was selected to replace those identified as ineligible (by phone or questionnaire). The deadline for returning completed questionnaires was April 2014. 
2.4. Statistical Analysis. A sample size of 500 physicians was required to obtain a precision of $\pm 5 \%$ for endorsement proportions of $50 \%$. Assuming a $60 \%$ response rate, the questionnaire was sent to 838 physicians.

The distribution of endorsement was presented as median (25\%, 75\%), after adjustment for the stratified sampling of physicians by specialty (91.0\% for family physicians, $7.6 \%$ pediatricians, and $1.4 \%$ emergency physicians); we illustrated key results with diverging stacked bar charts [31]. We classified physicians as "intenders" or "nonintenders" based on their reported behaviour on the selected clinical vignette to prescribe long-term asthma controller for at least 3 months or until the patient sees his/her treating physician. Physicians were deemed to be in "strong agreement" if they responded 4 or 5 on the Likert-like scale of 0 to 5 . We explored the determinants of physicians' intention to prescribe long-term ICS, using bivariate logistic regression analyses to identify those significantly associated with the outcome; these were offered as candidate variables in the multivariate logistic regression analysis, forcing medical specialty in the model. Potential determinants included the following: physician characteristics; selected vignette; assessment of control; treatment goals; comfort level with initiating long-term ICS; and level of hesitation about risk-benefit of long-term ICS in various patients. All tests were two-sided with estimates presented with 95\% confidence intervals. Analyses were performed on SAS ${ }^{\circledR} 9.3$ software (SAS Institute Inc., Cary, NC 27513, USA). $P$ values less than 0.05 indicated statistical significance, with no correction for multiple testing and no imputation for missing data.

\section{Results}

The survey was sent to 838 physicians: 525 family physicians, 210 pediatricians, and 103 emergency physicians. After excluding 90 (10.7\%) noneligible physicians, 421 (56\%) of 748 potentially eligible physicians returned the completed questionnaire (Figure 1). Nonrespondents were similar to the respondents in specialty and practice area but had been in practice for a median of 7 years longer with a higher proportion of males (Table E2). Participants were predominantly women (69\%), working in an urban environment (93\%) and nonacademic institution (44\%); patients with asthma represented about a quarter of their clientele (Table 1 ).

Approximately $60 \%$ of participants selected the acutecare vignettes, with the remainder, the clinic vignettes, equally distributed between the pediatric and adult cases. Characteristics of respondents selecting each clinical vignette, their assessment, and intended prescription are displayed in Table E3. Although nearly all physicians recognised the suboptimal asthma control, about a quarter of respondents perceived the patient as having intermittent symptoms. The overwhelming majority (94.2\%) would prescribe an asthma controller, usually ICS, as monotherapy or combination therapy, and $86.0 \%$ would prescribe the controller for long-term use. Short-term treatment objectives were sought by most, particularly in acute-care vignettes, yet the overwhelming majority of physicians also reported long-term treatment goals.
TABLE 1: Characteristics of respondents.

\begin{tabular}{|c|c|}
\hline & $\begin{array}{l}\text { Participants } \\
(N=421)\end{array}$ \\
\hline Male sex, $n(\%)$ & $131(31)$ \\
\hline Years in practice, median $(25 \%, 75 \%)$ & $13(5,21)$ \\
\hline \multicolumn{2}{|l|}{ Speciality, $n(\%)$} \\
\hline Family medicine & $250(60)$ \\
\hline Pediatrics & $115(27)$ \\
\hline Emergency medicine & $56(13)$ \\
\hline \multicolumn{2}{|l|}{ Primary practice location, $n(\%)$} \\
\hline Urban & $390(93)$ \\
\hline Rural & $31(7)$ \\
\hline \multicolumn{2}{|l|}{ Completed training, $n(\%)^{*}$} \\
\hline Family medicine (residency) & $272(65)$ \\
\hline Pediatrics (residency or fellowship) & $121(29)$ \\
\hline Respirology (residency or fellowship) & $117(28)$ \\
\hline $\begin{array}{l}\text { Emergency medicine (residency or } \\
\text { fellowship) }\end{array}$ & $69(16)$ \\
\hline Other (residency or fellowship) & $55(13)$ \\
\hline \multicolumn{2}{|l|}{ Practice setting, $n(\%)$} \\
\hline Clinic with appointment & $285(68)$ \\
\hline Walk-in clinic & $168(40)$ \\
\hline Emergency room & $168(40)$ \\
\hline Intensive care unit & $26(6)$ \\
\hline Hospital wards & $171(41)$ \\
\hline Home care & $40(10)$ \\
\hline Others & $77(18)$ \\
\hline $\begin{array}{l}\text { Proportion of clientele with asthma, median } \\
(25 \%, 75 \%)\end{array}$ & $27(18,27)$ \\
\hline $\begin{array}{l}\text { Proportion of children in clientele, median } \\
(25 \%, 75 \%)\end{array}$ & $55(9,82)$ \\
\hline Practice in an asthma clinic, $n(\%)$ & $13(3)$ \\
\hline Self-reported being an asthma specialist, $n(\%)$ & $50(12)$ \\
\hline \multicolumn{2}{|l|}{ Usual work environment, $n(\%)$} \\
\hline Academic institution & $185(44)$ \\
\hline Nonacademic institution & $48(11)$ \\
\hline Private, group, or community practice & $187(45)$ \\
\hline
\end{tabular}

${ }^{*}$ The training completed was not mutually exclusive. Indeed, several physicians reported two or more training programs such as family medicine (or pediatric) with emergency medicine, a popular training to serve as general (or pediatric) emergency physicians.

Most physicians reported being comfortable with diagnosing asthma, distinguishing between intermittent and persistent asthma, assessing asthma control, and initiating long-term ICS, and reported low hesitation regarding the risk-benefit ratio of prescribing long-term ICS in the age group selected in the vignette. However, the overall comfort level was low for distinguishing between intermittent and persistent asthma without lung function tests, with significant hesitation regarding the risk-benefit ratio of prescribing longterm ICS in patients with intermittent or mild asthma (Table $\mathrm{E} 4)$. 


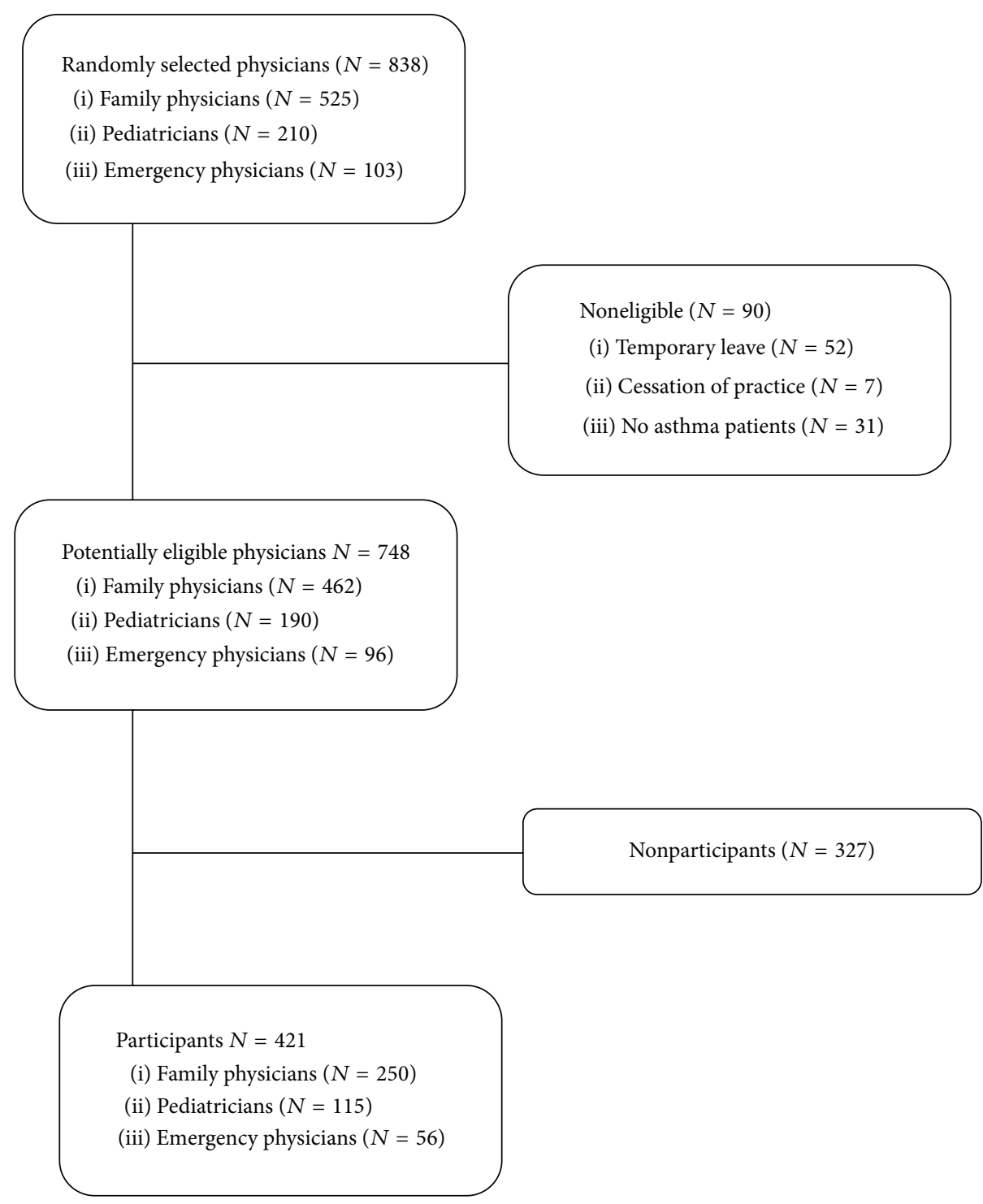

FIGURE 1: The flow of participants is depicted from screening to analysis.

The three most important determinants of the intention to prescribe a long-term controller, after adjustment for speciality, were the following: the physician's goal of achieving long-term asthma control, recognition of symptoms as being persistent, and comfort level in initiating a therapy of longterm ICS (Table 2). When the comfort level was removed as a candidate variable, it was replaced by low hesitation level regarding the risk-benefit of prescribing long-term ICS (Table E5).

The six enablers, previously identified by physicians to support their general management approach regarding longterm ICS use [26], are depicted in Figure 2. To increase their confidence in both the patient-specific indication for, and patient adherence to, long-term ICS, physicians strongly endorsed several resources, namely, patient asthma education, lung function tests, concordant recommendation by a specialist, and shared responsibility with paramedical healthcare professionals (nurses, certified asthma educators, pharmacists, and respiratory technicians) (Table 3). Most respondents did not know the expected delay to access these resources; when known, significant median delays were reported particularly for lung function testing (1-3 months) and consultation with an asthma specialist $(\geq 4$ months) (Figure E1). There was a strong interest in having a computerised system to identify delays to these resources in various areas and to be informed of novelties in asthma management $(96.1 \%)$, primarily by training days, distance online learning, and application for tablets/smartphones.

\section{Interpretation}

In this group of randomly selected Quebec physicians, most reported that they would prescribe a long-term asthma controller, predominantly ICS, to the poorly controlled patient depicted in their selected vignette. Physicians highly endorsed training and tools to support their 
TABLE 2: Multivariate analysis of intention of prescribing long-term asthma controller.

\begin{tabular}{|c|c|c|c|c|c|}
\hline & $\begin{array}{l}\text { Intenders } \\
(N=338)\end{array}$ & $\begin{array}{l}\text { Nonintenders } \\
\quad(N=82)\end{array}$ & $\begin{array}{l}\text { All cases } \\
\text { Odd ratios } \\
(95 \% \mathrm{CI})\end{array}$ & $\begin{array}{l}\text { Pediatric case } \\
\text { vignettes } \\
\text { Odd ratios } \\
(95 \% \mathrm{CI})\end{array}$ & $\begin{array}{c}\text { Adult case } \\
\text { vignettes } \\
\text { Odd ratios } \\
(95 \% \mathrm{CI})\end{array}$ \\
\hline \multicolumn{6}{|l|}{ Types of symptoms* $n(\%)$} \\
\hline Persistent & $281(83.1)$ & $49(59.8)$ & $2.67(1.54,4.63)$ & & $2.40(1.44,5.02)$ \\
\hline \multicolumn{6}{|l|}{ Treatment objective ${ }^{*}, n(\%)$} \\
\hline Improving long-term control & $298(88.4)$ & $42(51.2)$ & $5.31(2.74,10.3)$ & & $7.56(2.99,19.28)$ \\
\hline \multicolumn{6}{|c|}{ Level of comfort ${ }^{\dagger}$, median $(25 \%, 75 \%)$} \\
\hline $\begin{array}{l}\text { Initiating long-term inhaled } \\
\text { corticosteroids }\end{array}$ & $4.0(1.0,5.0)$ & $3.0(1.0,5.0)$ & $2.33(1.67,3.24)$ & $5.98(3.00,11.92)$ & $1.50(1.02,2.21)$ \\
\hline \multicolumn{6}{|l|}{ Specialty, $n(\%)$} \\
\hline Pediatrics & $104(30.8)$ & $11(13.4)$ & $0.87(0.43,1.77)$ & $0.59(0.24,1.43)$ & \\
\hline Emergency medicine & $31(9.2)$ & $25(30.5)$ & $0.81(0.43,1.54)$ & $0.91(0.32,2.62)$ & $0.64(0.28,1.46)$ \\
\hline Family medicine & $203(60.1)$ & $46(56.1)$ & 1 & 1 & 1 \\
\hline
\end{tabular}

Blank cells indicate that the variable was not statistically significant.

"Physicians who reported prescribing long-term ICS to the patient in their selected vignette were considered "intenders" in contrast to their counterparts, considered "nonintenders."

${ }^{*}$ Regarding the patient in their selected case vignette.

${ }^{\dagger}$ On a Likert scale of 0 (not comfortable at all) to 5 (very comfortable).

$\int$ Odds ratio adjusted for speciality.

TABLE 3: Resources that support physician's prescription of, and patient's compliance to, long-term inhaled corticosteroids (ICS).

\begin{tabular}{|c|c|c|c|c|}
\hline \multirow[t]{2}{*}{ Enablers } & $\begin{array}{c}\uparrow \text { physician's comfort } \\
\text { to prescribe } \\
\text { long-term ICS }\end{array}$ & $\begin{array}{l}\uparrow \text { patient adherence to } \\
\text { long-term ICS }\end{array}$ & Access to service & $\begin{array}{c}\text { Interest in } \\
\text { computerised system } \\
\text { to identify access } \\
\text { delay }\end{array}$ \\
\hline & $\begin{array}{l}\text { Adjusted proportion }{ }^{*} \\
\qquad(95 \% \mathrm{CI})\end{array}$ & $\begin{array}{l}\text { Adjusted proportion }{ }^{*} \\
(95 \% \mathrm{CI})\end{array}$ & $\begin{array}{l}\text { Adjusted proportion } \\
(95 \% \mathrm{CI})\end{array}$ & $\begin{array}{l}\text { Adjusted proportion* } \\
(95 \% \mathrm{CI})\end{array}$ \\
\hline Patient's asthma education & $65(59,71)$ & $95(93,98)$ & $86(80,90)$ & $67(62,73)$ \\
\hline $\begin{array}{l}\text { Finding the closest asthma education } \\
\text { centre }\end{array}$ & - & - & - & $81(77,86)$ \\
\hline $\begin{array}{l}\text { Lung function tests for school-aged } \\
\text { children/adults }\end{array}$ & $70(64,76)$ & $71(65,76)^{\ddagger}$ & $97(95,99)$ & $70(65,76)$ \\
\hline Lung function tests for preschoolers & $68(62,74)$ & & $47(38,56)$ & \\
\hline Concurrent opinion from a specialist & $71(65,77)$ & $62(57,66)$ & $96(93,98)$ & $70(65,76)$ \\
\hline Frequent follow-up visits & - & $66(60,71)$ & - & - \\
\hline Asthma clinic to refer patients & $78(73,83)$ & - & $60(53,67)$ & $71(65,72)$ \\
\hline \multicolumn{5}{|l|}{ Paramedical healthcare professional } \\
\hline $\begin{array}{l}\text { To guide patient in the treatment } \\
\text { plan }\end{array}$ & $78(73,83)$ & $92(88,95)$ & - & - \\
\hline $\begin{array}{l}\text { Available on site to provide asthma } \\
\text { education }\end{array}$ & $76(70,81)$ & - & $52(46,58)$ & - \\
\hline To share patient follow-up & - & - & $57(50,63)$ & - \\
\hline
\end{tabular}

*Values are reported as "adjusted proportion" of high endorsement, that is, 4 or 5 on the Likert scale, after adjustment for the stratified sampling of physicians by specialty, that is, weighting responses to reflect the distribution of physicians in the Province of Quebec using weights of $91.0 \%$ for family physicians, $7.6 \%$ for pediatricians, and $1.4 \%$ for emergency physicians.

"Values are reported as "adjusted proportion" of those that declared access, adjusted for the stratified sampling of physicians by specialty, as described above by ${ }^{*}$.

${ }^{\ddagger}$ Lung function testing for any age group.

'Including nurses, certified asthma educators, pharmacists, and respiratory technicians. 


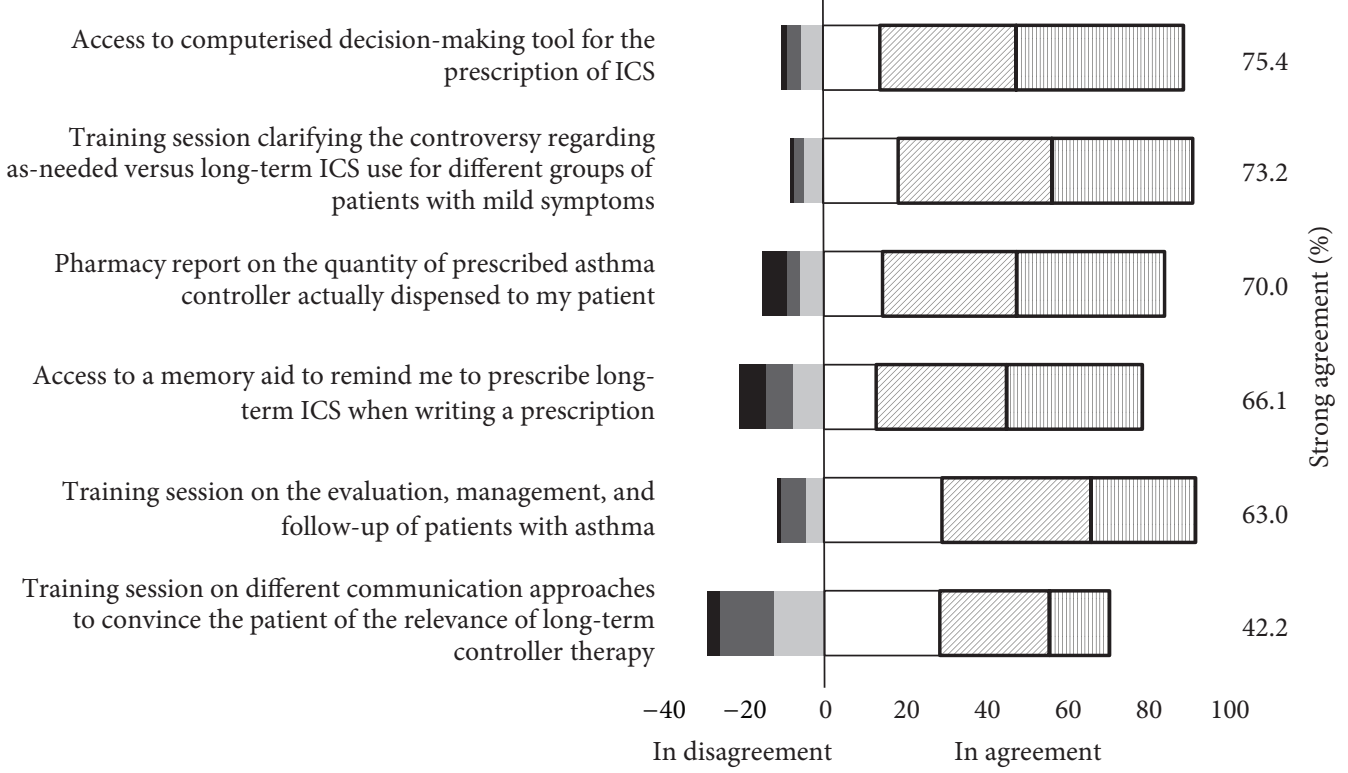

FIGURE 2: This histogram depicts the physicians' endorsement, adjusted for the sampling fraction, of each proposed enablers on a Likert-like scale ranging between 5 indicating strong agreement (vertical bars), 4 (diagonal grey bars), 3 (white), 2 (light grey), 1 (medium grey), and 0 indicating strong disagreement (black). The proportion of participants with strong endorsement, that is, answering 4 or 5 , is identified by a dark box in the histogram and displayed in the right column.

general management approach. With regard to patientspecific decision-making, key enablers to improve their comfort level in prescribing, and perceived patient adherence to, long-term ICS included the following: patient asthma education, lung function testing, concordant opinion by a specialist, having access to an asthma clinic to refer patients, and paramedical healthcare professionals to assist in guided self-management. The most important features distinguishing physicians who would prescribe a long-term asthma controller were the recognition of symptoms as being persistent, their high comfort level in initiating longterm ICS, and their goal of improving long-term asthma control. The substitution of comfort level in, by less hesitation regarding the risk-benefit ratio of, prescribing long-term ICS suggested that the latter is inversely and closely related to the former.

The strong endorsement of specific training sessions, decision-support tools, reminders, and pharmacy reports of drug claims to support the general management approach is aligned with prior studies [32]. In these studies, physicians voiced, as barriers to optimal asthma management, their confidence about capabilities in prescribing, and beliefs about consequences of, long-term ICS, as well as their worry about patients' noncompliance and the absence of patient followup $[10,33,34]$. In addition, key resources that increase physician's reported comfort in prescribing long-term ICS and perceived patient adherence were endorsed for patientspecific management, presumably because of more certainty in the management decision (i.e., lung function testing, specialist's opinion, and access to an asthma clinic), greater degree of collaborative care and patient follow-up (i.e., patient guidance and education provided by a paramedical healthcare professional) [33]. A highly valued proposal was to provide computerised systems to identify the delay for access to these resources, a solution implemented with success for emergency wait time [35]. Most strongly endorsed enablers have been shown to be effective to improve physicians' prescription in general, and of asthma controllers specifically, namely, facilitated workshops (by improving knowledge, attitude, skills, and beliefs) [36], decision-support tools [32] and, to a lesser extent, reminders [37], and organisational changes [32].

With over four-fifths prescribing long-term asthma controller to their patient in the clinical vignettes, the prescription behaviour was highly concordant with recent national and international guidelines $[1,4,38]$. Yet, it contrasted with published prescription patterns varying between $17 \%$ and $69 \%$ of patients receiving ICS in Quebec and elsewhere [10, $15,39]$, often with inadequate number of renewals to enable long-term use $[15,16]$. The latter suggests more emphasis on physician's short-term treatment goals and/or suboptimal prescription filling by patients [39]. Although reported prescribing behaviour may overestimate real practice patterns, the apparent discrepancy with prescriptions studies may be due in part to the fact that poorly controlled patients as described in the vignettes may represent a small proportion of patients enrolled in drug claim data; alternatively it may reflect evolving practice patterns [40].

In contrast to prior reports indicating the lowest use of long-term asthma controller by emergency physicians compared to family physicians and other specialists $[10,27$, 33,39 ], specialty or practice setting was not important in the multivariate analysis. Indeed, physicians' perceived patient need for ICS, treatment goals, confidence about capabilities in 
prescribing, and/or knowledge of risk-benefit regarding longterm ICS, all recognised domains for effective implementation of any health behaviour, appear to be the key operational constructs in the prescription of long-term ICS [27]. This is in line with prior reports, in which confidence about capabilities was associated with an 2.8 OR of prescribing ICS [10]. The strength of associations and consistency of predictors across age groups in our vignettes underline the robustness of the predictors of intention.

Despite a large sample size and the strength and precision of identified associations, we acknowledge the following study limitations. Consistent with prior physician surveys, there was a slight overrepresentation of female physicians and, importantly, those in practice for a shorter period [41]; findings may thus reflect more the practice of physicians trained under recent guidelines than those trained when guidelines and teaching methods were different. We acknowledge the possibility of a social desirability bias, that is, the tendency for physicians to report the perceived desired response rather than their true behaviour, which would overestimate actual use of ICS. To minimise such bias, we provided a large range of response options for management questions in vignettes and reversed questions, asking first about management and last about patient assessment and treatment goals. Recent data showing concordance in determinants of prescription of ICS, such as those observed in this study, suggest generalizability [10].

The study was conducted in Quebec where there is free access to medical care, free patient asthma education, and a subsidised drug plan for residents. Despite our long questionnaire, our $56 \%$ response rate $(59 \%$, assuming that $11 \%$ of nonresponders were ineligible as noted among those reached) is within expected standards (54\%-60\%) for physician surveys, in which higher response rates are generally not associated with less bias [41]. Our objective to have a representative sample of physicians treating patients with asthma resulted in a large proportion of respondents being family physicians. Their frequent selection of the acute-care and pediatric vignettes suggests that an important proportion of these patients are indeed treated by family physicians in Quebec, which may not be applicable to other countries. Caution is thus advised before generalization of the study results to other healthcare settings or specialties.

The overwhelming majority of surveyed physicians reported prescribing long-term ICS to the poorly controlled patient in the clinical vignette, attesting to their intention. In line with the observed determinants of intention, training sessions and decision-support tools to improve physician recognition of persistent symptoms, the importance of longterm asthma control, and confidence in, or knowledge about the risk-benefits of, initiating long-term ICS carry the best chance of improving the rate of long-term ICS prescriptions in patients with persistent asthma. Enhancing access to key resources to support patient-specific management decisions appears to be crucial enablers to optimal asthma management and may lead to greater patient adherence. The physicianendorsed strong enablers provide important insights into design promising implementation interventions to improve long-term ICS prescription.

\section{Abbreviations}

ICS: Inhaled corticosteroids.

\section{Disclosure}

This work was presented in part at the annual Canadian Paediatric Society meeting, June 2014, Toronto, Canada.

\section{Competing Interests}

The authors declare that they have no competing interests.

\section{Acknowledgments}

This work was funded through a research Grant (no. 233813) awarded through a peer-review process by the Canadian Institutes of Health Research (CIHR), Canada. The authors acknowledge the support of the Fonds de la Recherche du Québec en Santé for the infrastructure support provided to the Research Institute of the Centre Hospitalier Universitaire Sainte-Justine (CHUSJ). They are indebted to the Lucie Bergeron and Johanne St-Pierre for providing the list of the College des Médecins du Québec, Benoit Mâsse for preparing the randomisation list, and Katia Lessard, Bhupendrasinh Chauhan, Megan Jensen, Marie-France Goyer, and Annie Théorêt for assisting with the mailing of questionnaires and/or phoning of participants. They thank Annie Théorêt for assistance in paper preparation.

\section{References}

[1] GINA Global Initiative for Asthma Program, Global Strategy for Asthma Management and Prevention, Global Initiative for Asthma, 2014, http://www.ginasthma.org/.

[2] British Thoracic Society Scottish Intercollegiate Guidelines Network, "British Thoracic Society Scottish Intercollegiate Guidelines Network. British guideline on the management of asthma," Thorax, vol. 69, pp. il-i192, 2014.

[3] M. D. Lougheed, C. Lemiere, F. M. Ducharme et al., "Canadian Thoracic Society 2012 guideline update: diagnosis and management of asthma in preschoolers, children and adults," Canadian Respiratory Journal, vol. 19, no. 2, pp. 127-164, 2012.

[4] National Asthma Education Prevention Program, NAEPP Expert Panel Report-Guidelines for the Diagnosis and Management of Asthma-Update on Selected Topics 2007, NIH publication No 02-5075, 2007.

[5] National Asthma Control Initiative, Putting Guideline Priorities into Action, 2013, https:/www.nhlbi.nih.gov/health-pro/ resources/lung/naci/discover/priorities.htm.

[6] W. M. Vollmer, L. E. Markson, E. O’Connor et al., "Association of asthma control with health care utilization and quality of life," American Journal of Respiratory and Critical Care Medicine, vol. 160, no. 5, pp. 1647-1652, 1999.

[7] L.-P. Boulet, R. A. McIvor, and D. Marciniuk, "Respiratory guidelines implementation in Canada," Canadian Respiratory Journal, vol. 14, no. 6, pp. 329-330, 2007.

[8] R. A. McIvor, L. P. Boulet, J. M. FitzGerald, S. Zimmerman, and K. R. Chapman, "Asthma control in Canada: no improvement 
since we last looked in 1999," Canadian Family Physician, vol. 53, no. 4, pp. 672-677, 2007.

[9] J. M. FitzGerald, L.-P. Boulet, R. A. Mclvor, S. Zimmerman, and K. R. Chapman, "Asthma control in Canada remains suboptimal: the reality of asthma control (TRAC) study," Canadian Respiratory Journal, vol. 13, no. 5, pp. 253-259, 2006.

[10] J. P. Wisnivesky, J. Lorenzo, R. Lyn-Cook et al., "Barriers to adherence to asthma management guidelines among innercity primary care providers," Annals of Allergy, Asthma and Immunology, vol. 101, no. 3, pp. 264-270, 2008.

[11] K. F. Rabe, M. Adachi, C. K. W. Lai et al., "Worldwide severity and control of asthma in children and adults: the global asthma insights and reality surveys," Journal of Allergy and Clinical Immunology, vol. 114, no. 1, pp. 40-47, 2004.

[12] J. Cane, D. O'Connor, and S. Michie, "Validation of the theoretical domains framework for use in behaviour change and implementation research," Implementation Science, vol. 7, article 37, 2012 .

[13] R. K. Cydulka, J. H. Tamayo-Sarver, C. Wolf, E. Herrick, and S. Gress, "Inadequate follow-up controller medications among patients with asthma who visit the emergency department," Annals of Emergency Medicine, vol. 46, no. 4, pp. 316-322, 2005.

[14] F. M. Ducharme, R. L. Zemek, D. Chalut et al., "Written action plan in pediatric emergency room improves asthma prescribing, adherence, and control," American Journal of Respiratory and Critical Care Medicine, vol. 183, no. 2, pp. 195-203, 2011.

[15] L. Blais and M.-F. Beauchesne, "Use of inhaled corticosteroids following discharge from an emergency department for an acute exacerbation of asthma," Thorax, vol. 59, no. 11, pp. 943-947, 2004.

[16] S. Pando, C. Lemière, M.-F. Beauchesne, S. Perreault, A. Forget, and L. Blais, "Suboptimal use of inhaled corticosteroids in children with persistent asthma: inadequate prescription, poor drug adherence, or both?" Pharmacotherapy, vol. 30, no. 11, pp. 1109-1116, 2010.

[17] F. M. Ducharme, F. J. D. Noya, F. C. Allen-Ramey, E. M. Maiese, J. Gingras, and L. Blais, "Clinical effectiveness of inhaled corticosteroids versus montelukast in children with asthma: prescription patterns and patient adherence as key factors," Current Medical Research and Opinion, vol. 28, no. 1, pp. 111-119, 2012.

[18] Y.-Y. Meng, K.-M. Leung, D. Berkbigler, R. J. Halbert, and A. P. Legorreta, "Compliance with US asthma management guidelines and specialty care: a regional variation or national concern?" Journal of Evaluation in Clinical Practice, vol. 5, no. 2, pp. 213-221, 1999.

[19] J. A. Finkelstein, P. Lozano, R. Shulruff et al., "Self-reported physician practices for children with asthma: are national guidelines followed?” Pediatrics, vol. 106, no. 4, pp. 886-896, 2000.

[20] M. D. Cabana, C. S. Rand, N. R. Powe et al., "Why don't physicians follow clinical practice guidelines?: a framework for improvement," The Journal of the American Medical Association, vol. 282, no. 15, pp. 1458-1465, 1999.

[21] C. E. Baena-Cagnani, W. E. Berger, L. M. DuBuske et al., "Comparative effects of desloratadine versus montelukast on asthma symptoms and use of $\beta 2$-agonists in patients with seasonal allergic rhinitis and asthma," International Archives of Allergy and Immunology, vol. 130, no. 4, pp. 307-313, 2003.

[22] M. D. Cabana, B. E. Ebel, L. Cooper-Patrick, N. R. Powe, H. R. Rubin, and C. S. Rand, "Barriers pediatricians face when using asthma practice guidelines," Archives of Pediatrics and Adolescent Medicine, vol. 154, no. 7, pp. 685-693, 2000.

[23] J. M. Grimshaw, R. E. Thomas, G. MacLennan et al., "Effectiveness and efficiency of guideline dissemination and implementation strategies," Health Technology Assessment, vol. 8, no. 6, pp. 30-72, 2004.

[24] J. M. Grimshaw, L. Shirran, R. Thomas et al., "Changing provider behavior: an overview of systematic reviews of interventions," Medical Care, vol. 39, no. 8, pp. II2-II45, 2001.

[25] S. K. Bhogal, D. McGillivray, J. Bourbeau et al., "Focusing the focus group: impact of the awareness of major factors contributing to non-adherence to acute paediatric asthma guidelines," Journal of Evaluation in Clinical Practice, vol. 17, no. 1, pp. 160-167, 2011.

[26] A. J. Lamontagne, S. Peláez, R. Grad et al., "Facilitators and solutions for practicing optimal guided asthma self-management: the physician perspective," Canadian Respiratory Journal, vol. 20, no. 4, pp. 285-293, 2013.

[27] M. D. Cabana, H. Abu-Isa, S. M. Thyne, and B. Yawn, "Specialty differences in prescribing inhaled corticosteroids for children," Clinical Pediatrics, vol. 46, no. 8, pp. 698-705, 2007.

[28] L. A. Bero, R. Grilli, J. M. Grimshaw, E. Harvey, A. D. Oxman, and M. A. Thomson, "Closing the gap between research and practice: an overview of systematic reviews of interventions to promote the implementation of research findings," The British Medical Journal, vol. 317, no. 7156, pp. 465-468, 1998.

[29] J. Grimshaw, M. Eccles, M. Campbell, and D. Elbourne, “Cluster randomized trials of professional and organizational behavior change interventions in health care settings," Annals of the American Academy of Political and Social Science, vol. 599, pp. 71-93, 2005.

[30] D. A. Dillman, Mail and Internet Surveys: The Tailored Design Method, John Wiley \& Sons, New York, NY, USA, 2000.

[31] N. Robbins and R. M. Heiberger, "Plotting likert and other rating scales," in Proceedings of the Joint Statistical Meeting, pp. 1058-1066, NBR and Temple University, Miami, Fla, USA, JulyAugust 2011.

[32] S. O. Okelo, A. M. Butz, R. Sharma et al., "Interventions to modify Health care provider adherence to asthma guidelines: a systematic review," Pediatrics, vol. 132, no. 3, pp. 517-534, 2013.

[33] A. L. Andrews, R. J. Teufel, and W. T. Basco Jr., "Initiating inhaled steroid treatment for children with asthma in the emergency room: current reported prescribing rates and frequently cited barriers," Pediatric Emergency Care, vol. 29, no. 9, pp. 957962, 2013.

[34] M. D. Cabana, C. S. Rand, O. J. Becher, and H. R. Rubin, "Reasons for pediatrician nonadherence to asthma guidelines," Archives of Pediatrics and Adolescent Medicine, vol. 155, no. 9, pp. 1057-1062, 2001.

[35] R. Resar, K. Nolan, D. Kaczynski, and K. Jensen, "Using realtime demand capacity management to improve hospitalwide patient flow," Joint Commission Journal on Quality and Patient Safety, vol. 37, no. 5, pp. 217-227, 2011.

[36] S. D. French, S. E. Green, D. A. O'Connor et al., "Developing theory-informed behaviour change interventions to implement evidence into practice: a systematic approach using the Theoretical Domains Framework," Implementation Science, vol. 7, article 38, 2012.

[37] K. G. Shojania, A. Jennings, A. Mayhew, C. R. Ramsay, M. P. Eccles, and J. Grimshaw, "The effects of on-screen, point of care computer reminders on processes and outcomes of care," 
Cochrane Database of Systematic Reviews, no. 3, Article ID CD001096, 2009.

[38] F. M. Ducharme, S. D. Dell, D. Radhakrishnan et al., "Diagnosis and management of asthma in preschoolers: a Canadian Thoracic Society and Canadian Paediatric Society position paper," Paediatrics and Child Health, vol. 20, no. 7, pp. 135-143, 2015.

[39] A. L. Andrews, R. J. Teufel II, and W. T. Basco Jr., "Low rates of controller medication initiation and outpatient follow-up after emergency department visits for asthma," Journal of Pediatrics, vol. 160, no. 2, pp. 325-330, 2012.

[40] A. L. Andrews, W. S. Russell, M. O. Titus et al., "Quality improvement methods improve inhaled corticosteroid prescribing in the emergency department," Journal of Asthma, vol. 51, no. 7, pp. 737-742, 2014.

[41] T. Flanigan, E. McFarlane, and S. Cook, "Conducting survey research among physicians and other medical professionals: a review of current literature," in Proceedings of the Survey Research Methods Section (AAPOR '08), pp. 4136-4147, American Statistical Association, New Orleans, La, USA, 2008. 


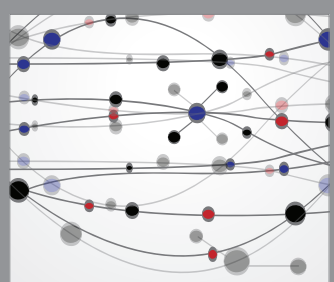

The Scientific World Journal
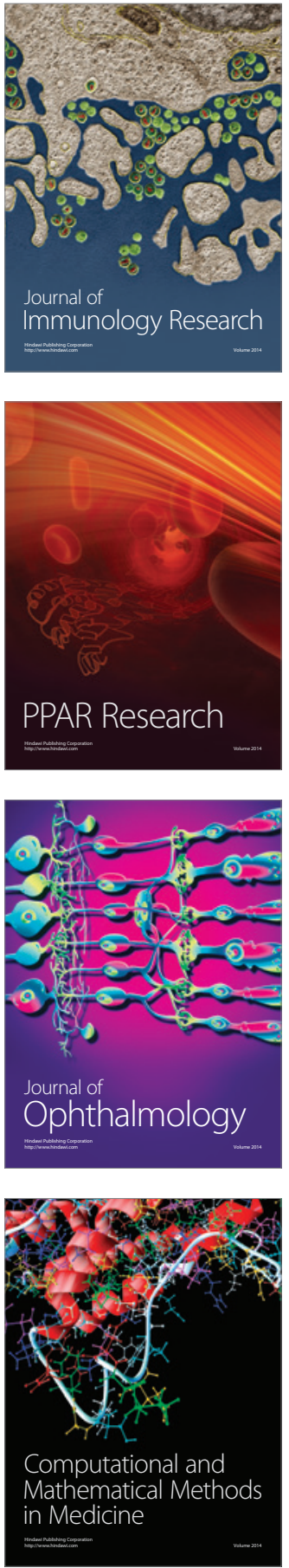

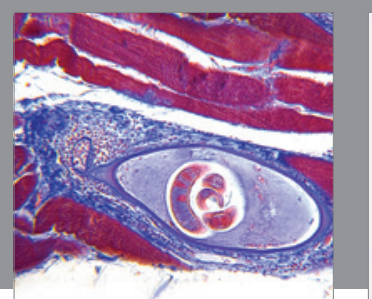

Gastroenterology Research and Practice

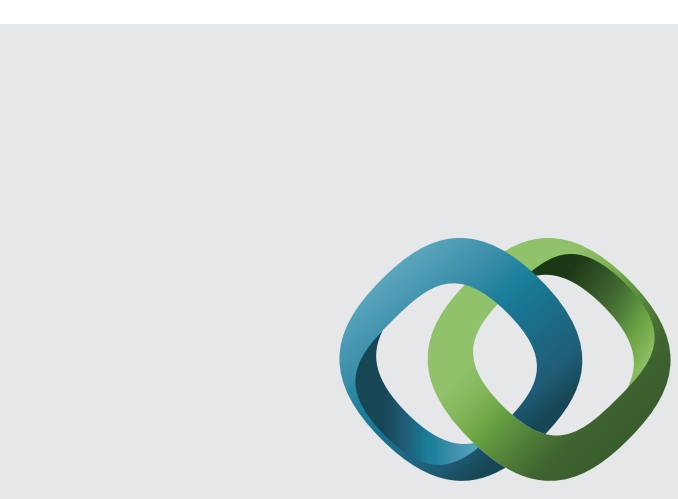

\section{Hindawi}

Submit your manuscripts at

http://www.hindawi.com
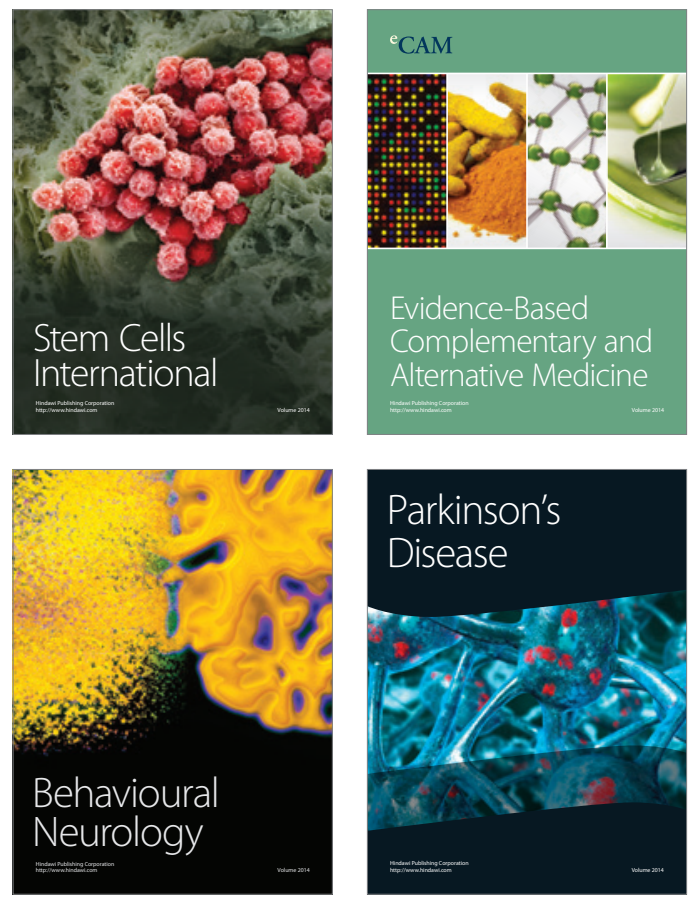
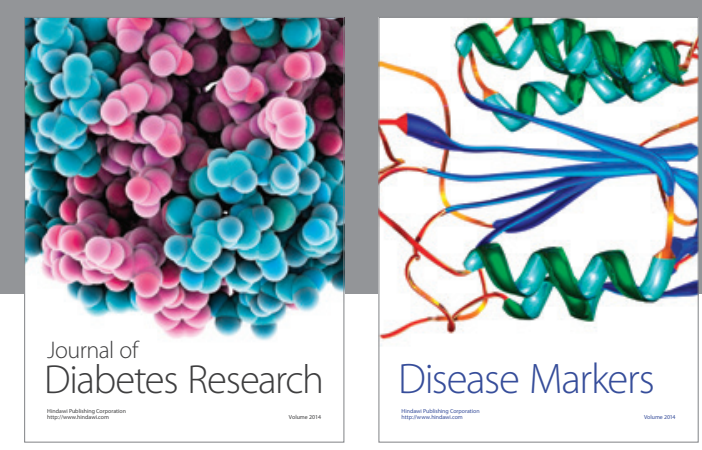

Disease Markers
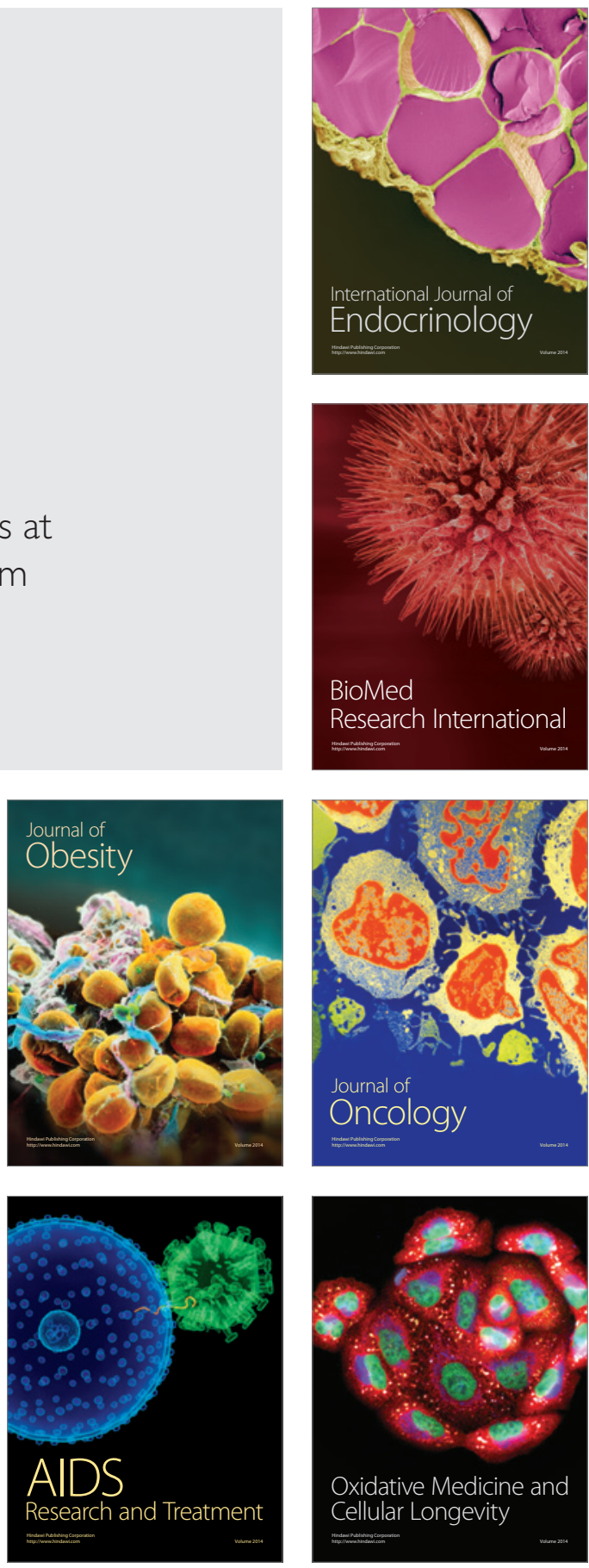